Regular Paper

\title{
Examination of the Inductance Method for Non-Destructive Testing in Structural Metallic Material by Means of the Pancake-type Coil
}

\author{
Mohachiro OKA $^{* 1}$, Terutoshi YAKUSHIJI ${ }^{* 1}$, Yuji TSUCHIDA ${ }^{* 2}$ and Masato ENOKIZONO ${ }^{* 2}$ \\ We have already proposed the fatigue evaluation method for the metallic material by measuring an inductance of \\ a pancake-type coil using a LCR meter. This method was called the inductance method. This time, we have improved \\ the conventional inductance method by using a low excitation frequency under a dc magnetic field generated by a \\ neodymium $(\mathrm{Nd})$ permanent magnet. The improved method was applied to the evaluation of a fatigue damage accu- \\ mulation caused by partially pulsating stress in an iron-based structural metallic material (SS400). The new method \\ was able to detect the change of the material condition such as a fatigue damage accumulation in SS400 without re- \\ ceiving the influence of the surface condition of the specimen. In this paper, we report the results of a fatigue damage \\ accumulation evaluation using the new inductance method.
}

Keywords: fatigue, SS400, pancake-type coil, inductance method, LCR meter, magnet.

(Received: 31 May 2012, Revised: 16 June 2013)

\section{Introduction}

It is known that a crack occurs because of a fatigue accumulation in a metallic material. Then, the metallic component that exists in our surroundings breaks because of the fatigue accumulation. The fatigue accumulation is generated by external cyclic stress and thermal cyclic stress. To prevent any serious accidents caused by the fatigue accumulation, a conventional nondestructive testing gave priority to the discovery of the minute crack that occurred in the metallic components. However, the period from the appearance of the minute cracks of metallic parts to destruction is generally short. If we can know of the fatigue accumulation before the crack initiation, the adequate time can be obtained to prevent accidents. Therefore, research to evaluate the fatigue accumulation before the crack occurs in the metallic component has been active in recent years. We are also researching an evaluation method for a fatigue accumulated in the iron-based structural materials using the electromagnetic phenomena.

Many fatigue evaluation methods are being researched by different researchers. It is one of the important topics in this field. It is well known that magnetism and the micro-structure of the material are closely related. Thus, the attempt to evaluate the material deterioration from the change in the Barkhausen noise has been performed [1, 2, 3]. Moreover, the magnetic property of the magnetic materials was evaluated by the minor loop of $B-H$ curve [4]. In such a research situation, our group has researched which deterioration in stainless steels and low carbon steel is evaluated by the residual magnetization method [5] and the eddy current

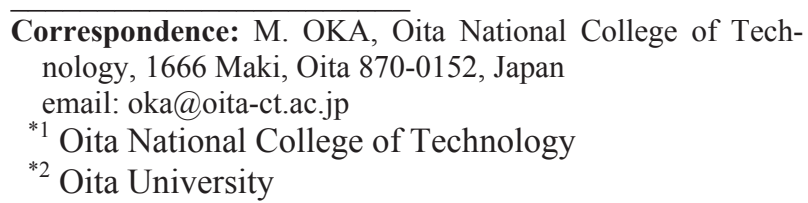

testing (ECT) method. In our previous research results, the ECT method attained good results in the detection of fatigue in the metallic components caused by the plane bending fatigue and partially pulsating stress $[6,7]$.

However, these fatigue evaluation methods using the ECT method still contain some problems. When the specimen is a magnetic material, its permeability is large and its resistivity is small. Then, the eddy current by excitation concentrates on the surface of the specimen due to the skin effect. The inside fatigue of the specimen is not appreciable. The ECT method that uses the high excitation frequency is not appropriate to evaluate the deep inside fatigue of a specimen. In addition, there is a problem in that the surface condition of the specimen strongly influences the result of the fatigue evaluation. It is necessary to solve these two problems. To solve the skin effect problem of the ECT method when the specimen was a magnetic material such as SS400, we devised the following two methods. The first device point is to use the low excitation frequency. In this paper, $10 \mathrm{kHz}$ were used as an excitation frequency. The other device points were to overlap the dc magnetic field to the alternating field with an $\mathrm{Nd}$ magnet. When a strong dc magnetic field was applied to the specimen, permeability was able to be reduced.

In order to evaluate the fatigue accumulation in an iron-based structural metallic material, we apply a nondestructive fatigue evaluation method for SS400 using the inductance method composed of a pancake-type coil that uses a low excitation frequency of about $10 \mathrm{kHz}$ and the dc magnetic field generated by the $\mathrm{Nd}$ magnet. This paper describes the new non-destructive fatigue evaluation method for SS400.

\section{Principle of the Inductance Method}

\subsection{The Principle of the Inductance Method}

Fig. 1 shows the principle of the inductance method that used a pancake-type coil. When a pancake-type coil 
is excited by an alternate current, an eddy current $\left(\boldsymbol{J}_{e}\right.$ $\left.\left(\mathrm{A} / \mathrm{m}^{2}\right)\right)$ is induced in a specimen as shown in Fig. 1. Then, the eddy current can be written as Eq. (1), where $\mu(\mathrm{H} / \mathrm{m})$ and $\rho(\Omega \mathrm{m})$ are permeability and resistivity of a specimen, respectively. Eq. (1) contains $\mu$ and $\rho$ of a specimen. Therefore, an eddy current in a specimen changes when electromagnetic properties such as $\mu$ and $\rho$ of a specimen changes by fatigue. An inductance $(L$ $(\mathrm{H}))$ of a pancake-type coil is influenced by the change of $\mu$ and $\rho$. If $L$ can be measured, we can know the amount of fatigue damage of a specimen.

$$
\nabla^{2} \boldsymbol{J}_{e}=\frac{\mu}{\rho} \frac{\partial \boldsymbol{J}_{e}}{\partial t} .
$$

\subsection{The Pancake-Type Coil}

Fig. 2 (a) shows dimensions of the pancake-type coil. Fig. 2 (b) shows the photograph of the pancake-type coil that is a same shape pancake-type coil used in the experiment. The number of turns in the pancake-type coil and the diameter of copper wire were 324 turns and $0.04 \mathrm{~mm}$, respectively. The inductance $(L)$ and impedance phase angle ( $\theta$ (degrees) $)$ of the pancake-type coil were $320.2 \mu \mathrm{H}$ and 22.9 degrees when it was in the air and the excitation frequency $\left(f_{\text {ex }}\right)$ was $10 \mathrm{kHz}$.

\section{Specimen and Experiment}

\subsection{The Specimen}

The specimen was made of hot rolled general structural steel (SS400). Fig. 3 shows the dimensions of a specimen and arrangement of the measurement area. Arrangements of $\mathrm{Nd}$ magnets are shown. The thickness of the specimen was about $1.2 \mathrm{~mm}$. To exclude residual stress caused by mechanical processing, specimens used in this experiment were cut in the shape shown in Fig. 3

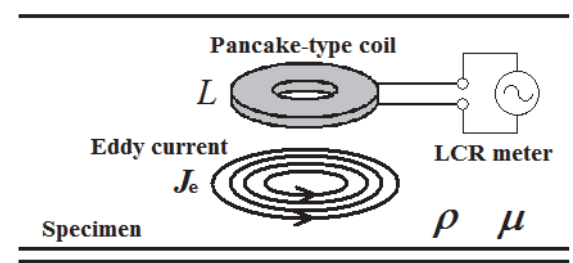

Fig. 1. The principle of the inductance method using the pancake-type coil.

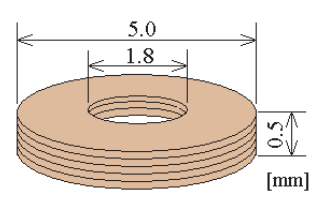

(a) Dimensions

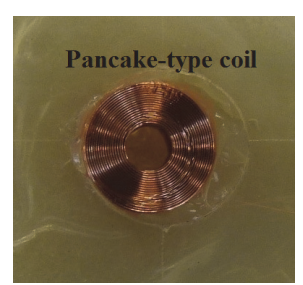

(b) Photograph
Fig. 2. The pancake-type coil used in the experiment. by the electrical discharge machining method. Tensile strength of this specimen was about $400 \mathrm{MPa}$. The specimen used for this experiment did not perform pretreating such as annealing.

The dc magnetic field was generated with an $\mathrm{Nd}$ magnet. Two Nd magnets were arranged to the series as shown in Fig. 3. The magnetic path was composed of two yokes made of SS400 and a specimen as shown in Fig. 3. The distance between the specimen and the upper side of the yoke was about $0.1 \mathrm{~mm}$. When the specimen was excluded, the magnetic flux density at the upper surface of the yoke was $220 \mathrm{mT}$.

Fig. 4 shows the photograph of the specimen with a surface scratch, when $N$ was $5 \times 10^{4}$. This scratch was caused in the specimen, and it is thought that depth was very slight.

\subsection{The Measurement System}

Fig. 5 shows the block diagram of a measurement system for the inductance method. The pancake-type coil constants such as $L$ and $\theta$ were measured by the LCR meter (ZM2353, NF Corporation). Measured values of $L$ and $\theta$ were a mean value of the measurement result of two times. The 4-terminal method was used to obtain accurate $L$ and $\theta$. These measuring devices were controlled by the control computer. Then, the values of $L$ and $\theta$ of the pancake-type coil were collected by the automatic operation.

\subsection{The Experimental Method}

To make a clear relationship among the amount of fatigue damage, $L$ and $\theta$, experiments were carefully carried out in the procedure shown in Fig. 6. First, $L$ and $\theta$ were measured by using the LCR meter within the

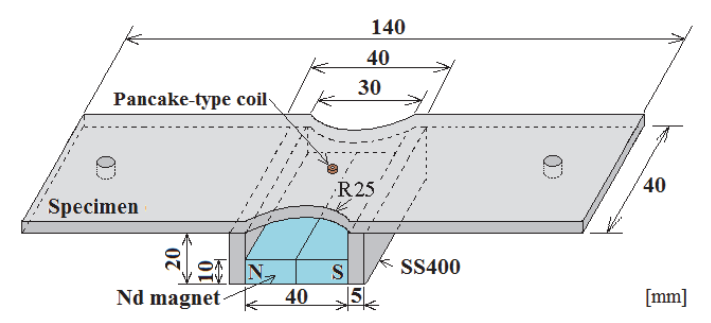

Fig. 3. The dimension of a specimen $(t=1.2 \mathrm{~mm})$ and arrangement of the pancake-type coil.

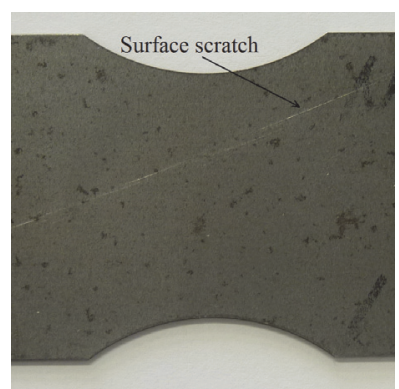

Fig. 4. Photograph of the specimen with a surface $\operatorname{scratch}(\mathrm{N}=5 \times 104)$. 
measurement area of $40 \mathrm{~mm}$ x $40 \mathrm{~mm}$ every $1 \mathrm{~mm}$ step. In our experiments, the excitation frequency and the excitation voltage were $10 \mathrm{kHz}$ and $1 \mathrm{~V}_{\text {rms }}$, respectively. The lift-off, which is the distance between the specimen and the lower side of the pancake-type coil, was about $0.05 \mathrm{~mm}$. Next, the partially pulsating stress was applied by the tensile and compression tester (V-0674, SAGINOMIYA SEISAKUSHO) which operated at 20 $\mathrm{Hz}$. The maximum tensile force was about $\pm 49 \mathrm{kN}$, and the maximum displacement amplitude was $30 \mathrm{~mm}$. This procedure was repeated until the specimen was destroyed. Fig. 7 shows the photograph of a specimen set in the tensile and compression tester.

This experiment was a fatigue test that impressed the partially pulsating stress to the specimen. The following experiments were executed when the stress ratio $(R)$ was 0.1 . In this experiment, a stress waveform was a sinusoidal wave. The experiments were performed at room temperature. The running average processing was applied to the values of $L$ and $\theta$ shown in this paper.

\subsection{S-N Curve of the Specimen}

In order to know the fatigue limit of our specimen, we measured the relationship between the partially pulsating stress $\left(\sigma_{\mathrm{a}}(\mathrm{MPa})\right)$ and the number of stress cycles $(N)$ ( $S$ - $N$ curve). This relationship is shown in Fig. 8. From Fig. 8, the fatigue limit of SS400 used in our experiments was estimated to be $110 \mathrm{MPa}$. The value of $\sigma_{\mathrm{a}}$ of the following experiments was decided using this $S-N$ curve. We used $100 \mathrm{MPa}, 110 \mathrm{MPa}, 115 \mathrm{MPa}, 120$ $\mathrm{MPa}$, and $125 \mathrm{MPa}$ as a value of $\sigma_{\mathrm{a}}$. When stress is the plane bending stress, fatigue of metal such as austenitic stainless steels progresses even if applied stress is below the fatigue limit $[8,9]$. Therefore, $100 \mathrm{MPa}$ was used as one of $\sigma_{\mathrm{a}}$.

\subsection{L and $\theta$ of the Pancake-Type Coil}

Table 1 shows the value of $L$ and $\theta$ under some conditions. These values were measured using a LCR meter (ZM2353) when $f_{\text {ex }}$ was $10 \mathrm{kHz} . L_{\mathrm{s}}$ is $L$ of the pancaketype coil on the center part of the specimen when the $\mathrm{dc}$ magnetic field was not applied, and $L_{\mathrm{m}}$ is $L$ of it on the center part of the specimen when the dc magnetic field was applied. When the pancake-type coil was in air, $L_{\mathrm{a}}$ is $L$ of it. $L_{\mathrm{s}}$ was influenced by $\mu$ and $\rho$ of the specimen and was larger than $L_{\mathrm{a}}$. However, because the magnetic

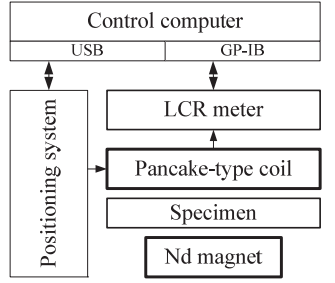

Fig. 5. The block diagram of a measurement system.

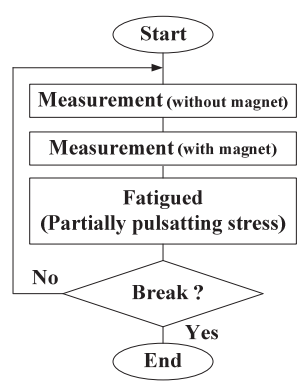

Fig. 6. Experimental procedure. flux density in the specimen is saturated by the dc magnetic field, $\mu$ in this case has become small. Therefore, $L_{\mathrm{m}}$ has become smaller than $L_{\mathrm{s}}$. When fatigue was applied to the specimen, $L$ and $\theta$ of the pancake-type coil are influenced also by $\rho$ of the specimen changed by fatigue.

\subsection{Skin Depth $(\delta)$}

Table 2 shows the skin depth $(\delta)$ under some conditions. The skin depth was calculated using the resistivity $\left(\rho=9.8 \times 10^{-8} \Omega \mathrm{m}\right)$ of the specimen and the excitation frequency $\left(f_{\mathrm{ex}}=10 \mathrm{kHz}\right)$. Here, relative permeability $\left(\mu_{\mathrm{r}}\right)$ of SS400 was assumed to be 200 when there was not a dc magnetic field. In this case, only fatigue near the surface of the specimen is evaluated. Moreover, the fatigue detection signal is strongly influenced by a scratch on the surface of the specimen. On the other hand, $\mu_{\mathrm{r}}$ was assumed to be ten in consideration of the influence of the magnetic saturation of the specimen when there was a dc magnetic field. If the dc magnetic field is applied, the skin depth grows very much as shown in Table 2. Therefore, if the dc magnetic field is applied, information on fatigue of the inside of the specimen can be obtained without receiving the influence of the surface condition of the specimen.

\section{Experimental Results and Discussions}

\subsection{The Distribution of L without or with Nd Magnet}

Fig. 9 (a) shows the distribution of $L$ at each measurement position when $\sigma_{\mathrm{a}}$ and the number of stress cycles $(N)$ were $115 \mathrm{MPa}$ and zero, respectively. Fig. 9 (b) shows the same relation as Fig. 8 (a), when $N$ was $2 \times 10^{6}$. In these cases, $\mathrm{Nd}$ magnets were not installed.

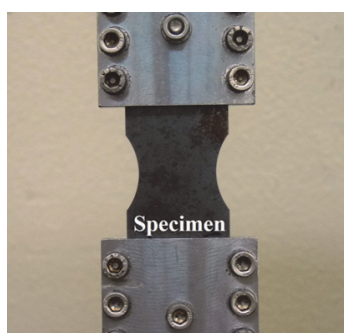

Fig. 7. Photograph of a specimen set in the tensile and compression tester.

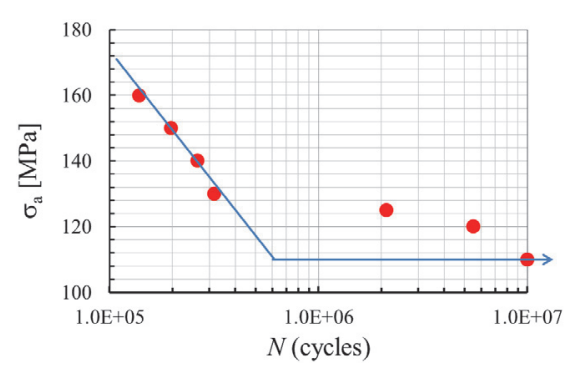

Fig. 8. The relationship between $\sigma_{\mathrm{a}}$ and $N$. 
The average value $\left(L_{\text {ave }}\right)$ of $L$ within $3 \mathrm{~mm} \times 3 \mathrm{~mm}$ of the central portion of the measurement range in Fig. 9 (a) was $463.7 \mu \mathrm{H}$. In Fig. 9 (b), $L_{\text {ave }}$ was $464.8 \mu \mathrm{H}$. However, this difference is not understood from both figures. In Fig. 10, the $L$ axis of this figure had expanded about 50 times compared with the $L$ axis of Fig. 9. Moreover, $d L$ was calculated by the following Eq. (2).

$$
d L=L-L_{a v e} .
$$

In Fig. 10, the distribution of $d L$ is not smooth due to non-homogeneity of the electromagnetic properties of the specimen. If Figs. 10 (a) and 10 (b) are compared, it is understood that $d L$ has changed by fatigue induced by partially pulsating stress. On the other hand, Fig. 11 shows the same relationship as Fig. 10. In Fig. 11, Nd magnets were installed. In Figs. 11 (a) and 11 (b), $L_{\text {ave }}$ were $410.5 \mu \mathrm{H}$ and $410.8 \mu \mathrm{H}$, respectively. When both figures are compared, the change in the distribution of $d L$ by fatigue cannot be clearly confirmed as in Fig. 10 . From Figs. 10 and 11, it can be said that the change of the specimen's electromagnetic properties ( $\rho$ and $\mu$ ) which was caused by fatigue due to partially pulsating stress was small.

\subsection{Influence of Surface Scratch on a Specimen}

Fig. 13 shows the distribution of $d L$ without $\mathrm{Nd}$ magnets when $f_{\mathrm{ex}}$ was $100 \mathrm{kHz}$. In this case, the skin depth was $35.2 \mu \mathrm{m}$. The scratch strongly influences the distribution of $d L$ in the inside of the black oval shown in Fig. 13. However, when $f_{\text {ex }}$ was $10 \mathrm{kHz}$, the influence of the scratch became small as shown in Fig. 14. In addition, when the dc magnetic field was applied, the influence of the scratch became even smaller as shown in Fig. 15. This phenomenon can be described by the following two reasons. The first reason is a decrease in the excitation frequency. The second reason is a decrease in permeability of the specimen by the magnetic saturation. It is well known that both reasons bring an increase in the skin depth.

\subsection{The Distribution of $\theta$}

Fig. 12 shows the distribution of $\theta$ at each measurement position. Nd magnets were not installed in Fig. 12 (a), and they were installed in Fig. 12 (b). When both figures are compared, the change in the distribution of $\theta$ by fatigue cannot be clearly confirmed.

Table 1. Values of $L$ and $\theta$ under some conditions

\begin{tabular}{|c|c|c|c|c|}
\cline { 2 - 5 } \multicolumn{1}{c|}{$f_{\mathrm{ex}}=10 \mathrm{kHz}$} & \multicolumn{2}{|c|}{$L[\mu \mathrm{H}]$} & $\theta$ [degrees] \\
\hline \multirow{2}{*}{ On specimen } & Without Magnet & $L_{\mathrm{s}}$ & 458.3 & 30.7 \\
\cline { 2 - 5 } & With Magnet & $L_{\mathrm{m}}$ & 406.0 & 26.9 \\
\hline \multicolumn{2}{|c|}{ In air } & $L_{\mathrm{a}}$ & 320.2 & 22.9 \\
\hline
\end{tabular}

Table 2. Skin depth $(\delta)$ under some conditions

\begin{tabular}{|c|c|c|}
\cline { 2 - 3 }$f_{\mathrm{ex}}=10 \mathrm{kHz}$ & $\mu_{\mathrm{r}}$ & Skin depth $\delta[\mu \mathrm{m}]$ \\
\hline Without magnet & 200 & 111 \\
\hline With magnet & 10 & 498 \\
\hline
\end{tabular}

\subsection{Relationship among $L_{\text {ave }}, \theta_{\text {ave }}, N$, and $\sigma_{\mathrm{a}}$}

In this paper, $L_{\text {ave }}$ was used as a parameter that evaluated fatigue in SS400.

Fig. 16 shows the relationship among $L_{\text {ave }}, N$, and $\sigma_{\text {a }}$ with $\mathrm{Nd}$ magnets when $f_{\text {ex }}$ was $10 \mathrm{kHz}$. Fig. 17 shows the same relation as Fig. 16 when the dc magnetic field was not applied. $L_{\text {ave }}$ has been somewhat changed by

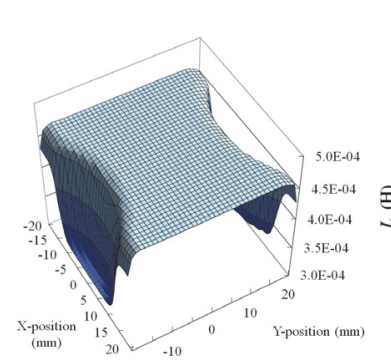

(a) $N=0$

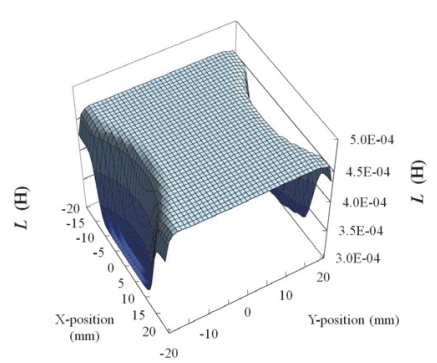

(b) $N=2 \times 10^{6}$
Fig. 9. Distribution of $\mathrm{L}$ without $\mathrm{Nd}$ magnet $(\sigma \mathrm{a}=115 \mathrm{MPa}$, fex $=10 \mathrm{kHz})$.

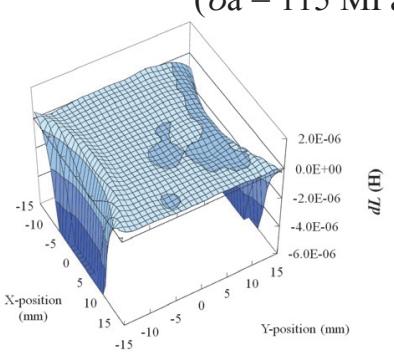

(a) $N=0$

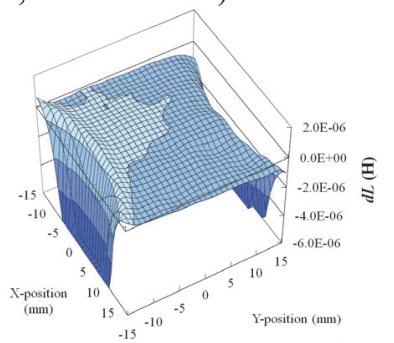

(b) $N=2 \times 10^{6}$
Fig. 10. Distribution of dL without $\mathrm{Nd}$ magnet $\left(\sigma_{\mathrm{a}}=115 \mathrm{MPa}, \mathrm{fex}=10 \mathrm{kHz}\right)$.

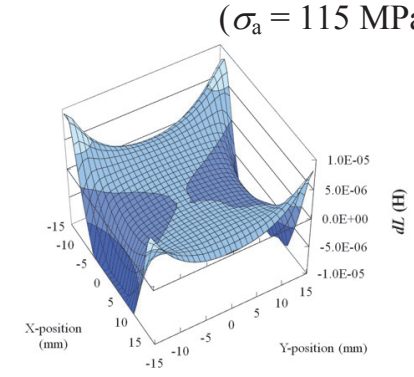

(a) $N=0$

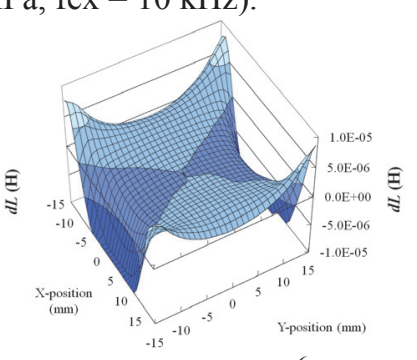

(b) $N=2 \times 10^{6}$
Fig. 11. Distribution of $d L$ with $\mathrm{Nd}$ magnet $\left(\sigma_{\mathrm{a}}=115 \mathrm{MPa}, f_{\mathrm{ex}}=10 \mathrm{kHz}\right)$.

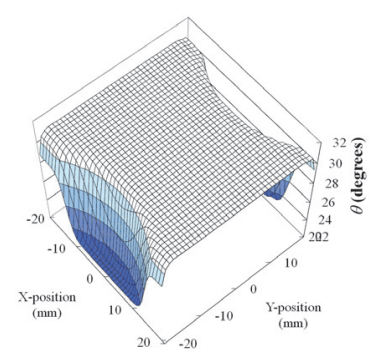

(a) Without magnet

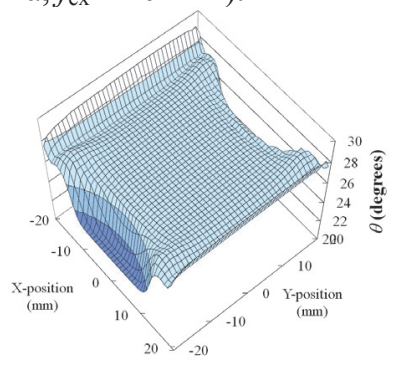

(b) With magnet
Fig. 12. Distribution of $\theta$ $\left(\sigma_{\mathrm{a}}=115 \mathrm{MPa}, f_{\mathrm{ex}}=10 \mathrm{kHz}, N=2 \times 10^{6}\right)$. 
fatigue in both figures. Therefore, there is a possibility that $L_{\text {ave }}$ can be used as a parameter that evaluates fatigue of SS400. Fig. 18 shows the relationship among $\theta_{\text {ave }}, N$, and $\sigma_{\mathrm{a}}$ with $\mathrm{Nd}$ magnets when $f_{\text {ex }}$ was $10 \mathrm{kHz}$. $\theta_{\text {ave }}$ was calculated as $L_{\text {ave }}$ in a similar method. The good correlation between $\theta_{\text {ave }}, \sigma_{\mathrm{a}}$, and $N$ doesn't exist in Fig. 18. Therefore, it cannot be said that $\theta_{\text {ave }}$ is a good parameter for the fatigue evaluation of SS400.

Figs. 19 and 20 were rewritten as having the same relation as Figs. 16 and 17 based on the value of $L_{\text {ave }}$ when $N$ was $1 \times 10^{4}$. In Fig. $19, d L_{\text {ave }}$ increases almost monotonously according to an increase in $N$, except when $\sigma_{\mathrm{a}}$ is $120 \mathrm{MPa}$. When the dc magnetic field was applied, permeability became very small. Then, the increase in the resistivity contributed more to $d L_{\text {ave }}$ than the decrease in permeability. This is the reason why $d L_{\text {ave }}$ increases almost monotonously. In Fig. $20, d L_{\text {ave }}$

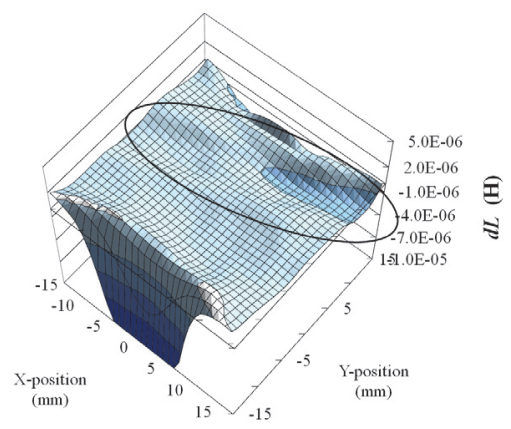

Fig. 13. Distribution of $d L$ without $\mathrm{Nd}$ magnet $\left(N=0, f_{\mathrm{ex}}=100 \mathrm{kHz}\right.$, With a scratch).

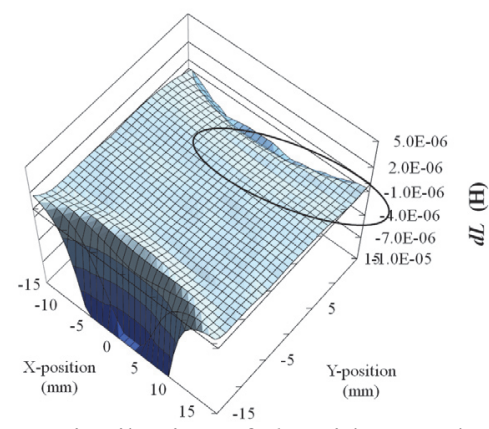

Fig. 14. Distribution of $d L$ without $N d$ magnet $\left(N=0, f_{\mathrm{ex}}=10 \mathrm{kHz}\right.$, With a scratch $)$.

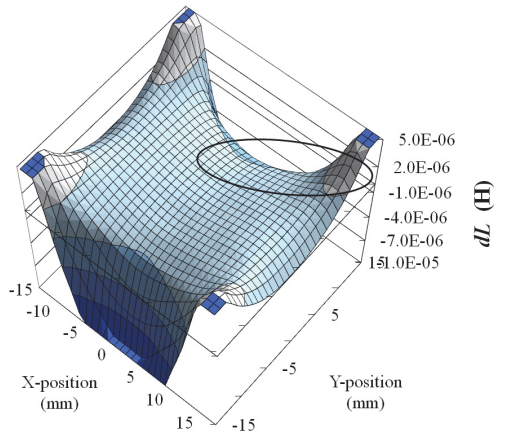

Fig. 15. Distribution of $d L$ with $\mathrm{Nd}$ magnet $\left(N=0, f_{\text {ex }}=10 \mathrm{kHz}\right.$, With a scratch). decreases with an increase in $N$ once, and tends to increase afterwards. In this case, the permeability of the specimen was large. Therefore, a decrease in permeability by fatigue greatly contributed to changing $d L_{\text {ave }}$ at the initial stage of fatigue. When $N$ grows, a decrease in permeability by fatigue was saturated. An increase in the resistivity contributes to the change of $d L_{\text {ave }}$ afterwards.

From these figures, $d L_{\text {ave }}$ under the dc magnetic field is proportional to $N$. Therefore, under the dc magnetic field it can be said that there is a possibility to be able to use $d L_{\text {ave }}$ as the parameter of the fatigue evaluation of SS400.

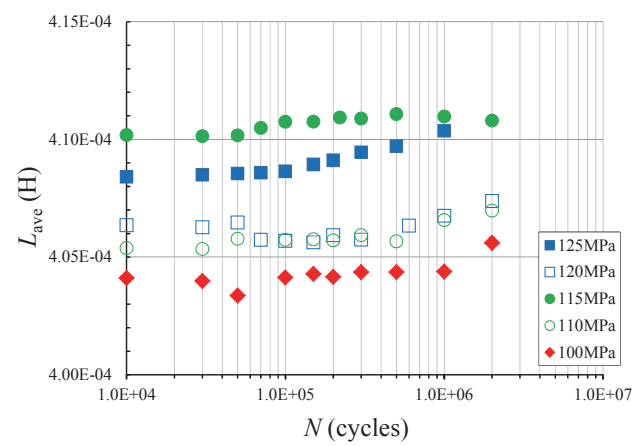

Fig. 16. Relationship among $L_{\text {ave }}, \sigma_{\mathrm{a}}$, and $N$ with $\mathrm{Nd}$ magnet $\left(f_{\mathrm{ex}}=10 \mathrm{kHz}\right)$.

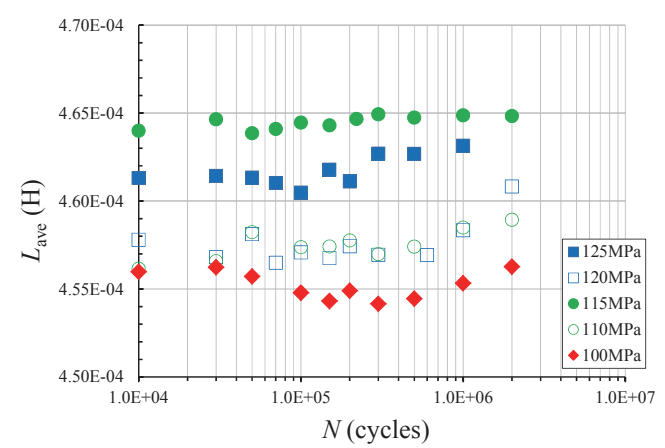

Fig. 17. Relationship among $L_{\text {ave }}, \sigma_{\mathrm{a}}$, and $N$ without $\mathrm{Nd}$ magnet $\left(f_{\mathrm{ex}}=10 \mathrm{kHz}\right)$.

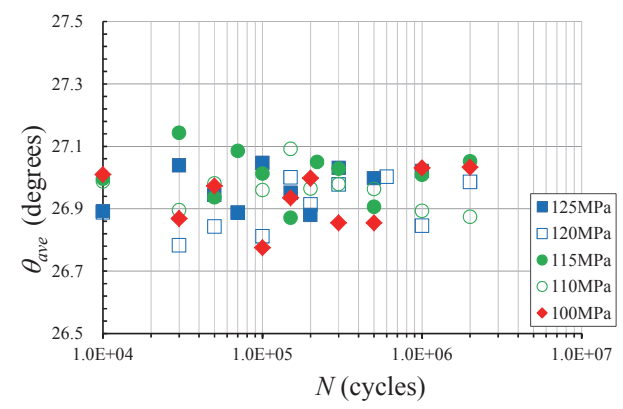

Fig. 18. Relationship among $\theta_{\text {ave }}$ of the pancake-type coil, $\sigma_{\mathrm{a}}$, and $N$ with $\mathrm{Nd}$ magnet $\left(f_{\mathrm{ex}}=10 \mathrm{kHz}\right)$. 


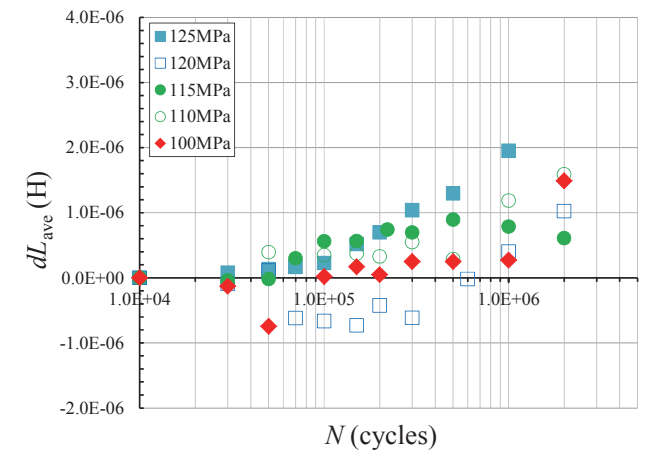

Fig. 19. Relationship among $d L_{\text {ave }}, \sigma_{\mathrm{a}}$, and $N$ with $\mathrm{Nd}$ magnet $\left(f_{\mathrm{ex}}=10 \mathrm{kHz}\right)$.

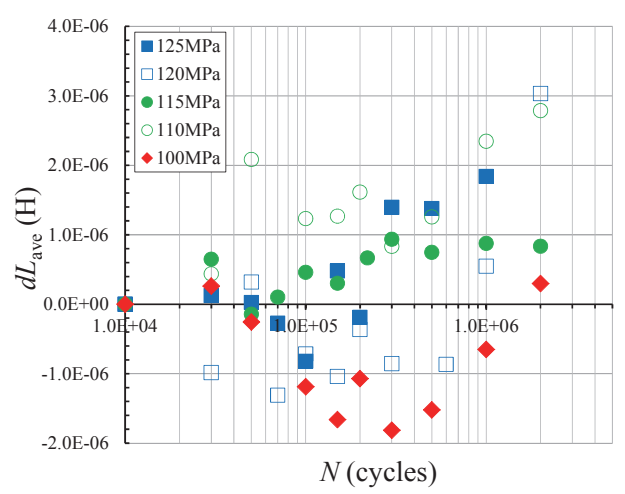

Fig. 20. Relationship among $d L_{\text {ave }}, \sigma_{\text {a }}$, and $N$ without $N d$ magnet $\left(f_{\mathrm{ex}}=10 \mathrm{kHz}\right)$.

\section{Conclusion}

In this paper, we applied the new inductance method to the fatigue evaluation of SS400. The new inductance method used for this experiment applied the low excitation frequency and the dc magnetic field. As a result, the correlation among the inductance of the pancake-type coil and the amount of fatigue damage of SS400 was obtained. This method was able to reduce the influence of the surface condition of the specimen. $d L_{\text {ave }}$ under the dc magnetic field can be used as the parameter of the fatigue evaluation of SS400. To increase the accuracy of fatigue evaluation in the magnetic materials, the improvement of the inductance method is needed in the future.

\section{Acknowledgment}

This work was supported in part by the Japan Society for the Promotion of Science under Grant No. 23560518 .

\section{References}

[1] Y. Furuya, H. Shimada, K. Yamada and T. Suzuki, "Estimation of Low Cycle Fatigue Process and Life by the Measurement of Magnetic Barkhausen Noise," J. Jpn. Soc. Non-destructive Inspection, Vol. 41, No.4, PP. 215218, 1992, (in Japanese).
[2] M. Kaplan, C. H. Gur and M. Erdogam, "Characterization of Dual-Phase Steels Using Magnetic Barkhausen Noise Technique," J. Nondestructive Evaluation, Vol. 26, PP. 79-87, 2007.

[3] Y. Tsuchida, T. Andou and M. Enokizono, "Fatigue Evaluation Based on Chaotic Attractors of Barkhausen Noise," J. Magn. Soc. Jpn., Vol. 26, pp. 756-768, 2002, (in Japanese).

[4] H. Kikuchi, A. Takahashi, L. Zhang, K. Ara, Y. Kamada and S. Takahashi, "NDE for Magnetic Material by Minor Loop Method Using Magnetic Yoke Probe," Electromag. Nondestructive Evaluation (IX), IOS Press, pp. 119-125, 2005.

[5] M. Oka, E. Wada, T. Yakushiji, Y. Tsuchida and M. Enokizono, "Evaluation of Fatigue Damage in SUS316 and SUS316L Using the FG Magnetic Sensor," Electromag. Nondestructive Evaluation (IX), IOS Press, pp. 159-165, 2005.

[6] M. Oka, Y. Tsuchida, T. Yakushiji and M. Enokizono, "Fatigue Evaluation for a Ferritic Stainless Steel (SUS430) by the Eddy Current Method Using the Pancake-Type Coil," IEEE Trans. Magn., Vol. 46, No. 2, pp. 540-543, 2010.

[7] M. Oka, T. Yakushiji, Y. Tsuchida and M. Enokizono, "Fatigue Evaluation of Low Carbon Steel by Means of the Inductance Method Using a Pancake-Type Coil," J. Jpn. Soc. Appl. Electromag. and Mech., Vol. 20, No. 2, pp.514-519, 2012.

[8] M. Oka, T. Yakushiji and M. Enokizono, "Fatigue Dependence of Residual Magnetization in Austenitic Stainless Steel Plates," IEEE Trans. Magn., Vol. 37, No. 5, pp. 3373-3375, 2001.

[9] M. Oka, E. Wada, T. Yakushiji, Y. Tsuchida and M. Enokizono, "Evaluation of Fatigue Damage in SUS316 and SUS316L Using the FG Magnetic Sensor," Studies in Appl. Electromag. and Mech. 25, Electromagn. Nondestructive Evaluation (IX), IOS Press, pp. 159-165, 2005. 